\title{
On body e-shaped patch antenna for biomedical application
}

\author{
Raja Rashidul Hasan', Raja Tariqul Hasan Tusher², Sujan Howlader ${ }^{3}$, Sharmin Jahan ${ }^{4}$ \\ 1,3,4 Department of EEE, American International University, Bangladesh \\ ${ }^{2}$ Department of CSE, Daffodil International University, Bangladesh
}

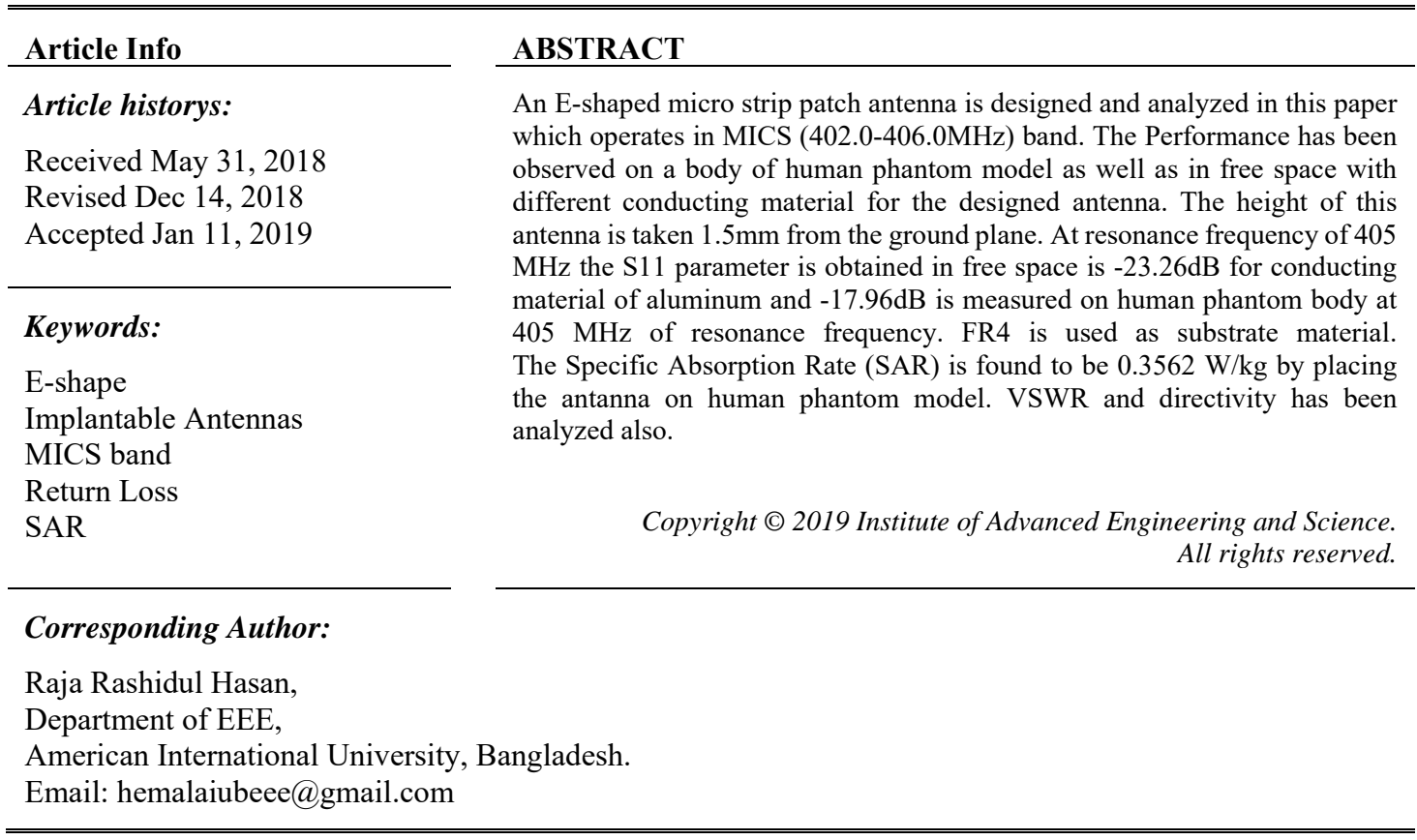

\section{INTRODUCTION}

The design of implantable patch antennas becoming more popular for dealing with issues related to biocompatibility, miniaturization and patient safety [1]. Peoples are now depending up on implantable medical devices for improving the quality of lives [2]. Furthermore, prototype fabrication of miniature antenna structures is highly challenging [3]. Biomedical sensors have also put a well remark on this field to operate successfully [4].

Recenty implantable antennas are use in drug pumps and nerve signal processing [5]. Wireless transmission is most commonly performed in the $402-405 \mathrm{MHz}$ frequency band, which has been exclusively allocated for medical implant communications systems (MICSs), is internationally available and feasible with low-power circuits [6]. In small antenna theory, as the radius of sphere including the full antenna structure increases,thelimitation of radiation efficiency increases [7]. To increase the performance of a microstrip patch antenna there are several methods like increasing the thickness of substrate, different impedance matching and feeding techniques [8]. It is challenging to design an antenna to operate in human tissue considering size, bandwidth, radiation efficiency, operating frequency, SAR and VSWR [9].

This paper proposed a patch antenna, whish is designed for appling medical sectors. A phantom muscel model is created according to dielectric properties of human body for performance analysis of this designed antenna. Performance is observed by placing the antenna on a phantom muscesl model and also in free space. During placing the antenna on a body model, silicon gel is used for safety. S11 (Return loss) and VSWR are observed by changing different conducting material. Radiation pattern and antenna performance in far field region is also observed. SAR is also measured for ensuring the safety in on-body applications. 


\section{RESEARCH METHOD}

Ground layer, substrate layer and the microstrip patch layer is used to design this antenna in free space. To get the MICS frequency band, the antenna is optimized by length, width, and also slot size.

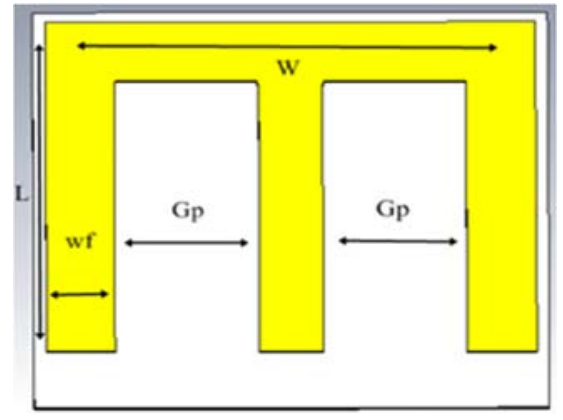

Figure 1. Designed E-shaped Antenna

The patch of the E shape antenna is designed width of $36 \mathrm{~mm}$ and the length is $32 \mathrm{~mm}$. Each layer thickness is designed with $0.5 \mathrm{~mm}$. For designing the antenna FR-4 substrate material is used. The patch material is considered as copper. Length and width were determined by equations of references forpatch of the antenna [10].

Table 1. Antenna Size Parameter

\begin{tabular}{cc}
\hline $\begin{array}{c}\text { Parameter and size for E-shaped } \\
\text { Parameter }\end{array}$ & Size \\
\hline W & $36 \mathrm{~mm}$ \\
L & $32 \mathrm{~mm}$ \\
Mt & $0.5 \mathrm{~mm}$ \\
Wf & $5.6 \mathrm{~mm}$ \\
H & $1.5 \mathrm{~mm}$ \\
$\mathrm{Gp}$ & $12.2 \mathrm{~mm}$ \\
\hline
\end{tabular}

\section{RESULTS AND ANALYSIS}

In CST microwave studio the input impedance is considered $50 \mathrm{ohms}$ for observing the antenna performance. The initial frequency was taken from 0 to $2 \mathrm{GHz}$.

\subsection{Simulated Result for E-shaped Antenna (free space)}

In free space, S11 parameter is observed for designed E-shaped micro strip patch antenna, which is shown in Figure 2. The value of $\mathrm{S} 11$ is obtained $-23.26 \mathrm{~dB},-17.32 \mathrm{~dB}$ and $-17.87 \mathrm{~dB}$ respectively for conducting material of aluminum, copper and gold. $505 \mathrm{MHz}$ is the middle frequency of the $(400-600 \mathrm{MHz})$ band and in this point, there is found to the minimum bandwidth of the total loss of human body [11].

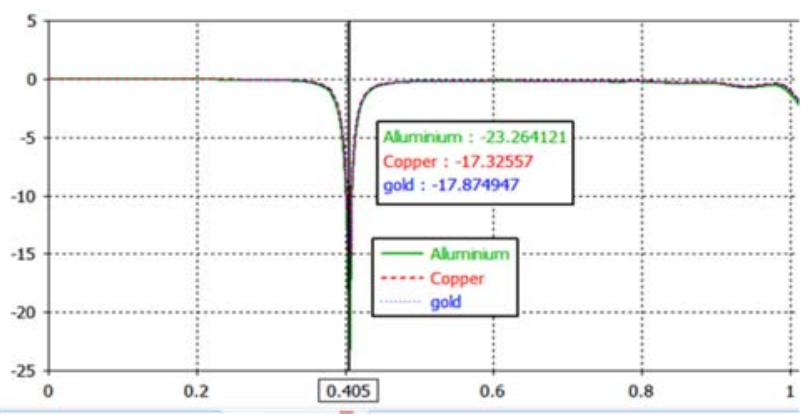

Figure 2. S11 parameter of E-shape antenna in free space 
The polar view of the E-shaped antenna is observed in Figure 3. Main lobe of an antenna means the maximum power containing of this lobe. There are also side lobe of the antenna. Here is shown the polar view and main lobe. The main lobe magnitude is found $1.47 \mathrm{dBi}$ and the direction is 110.4 degree.

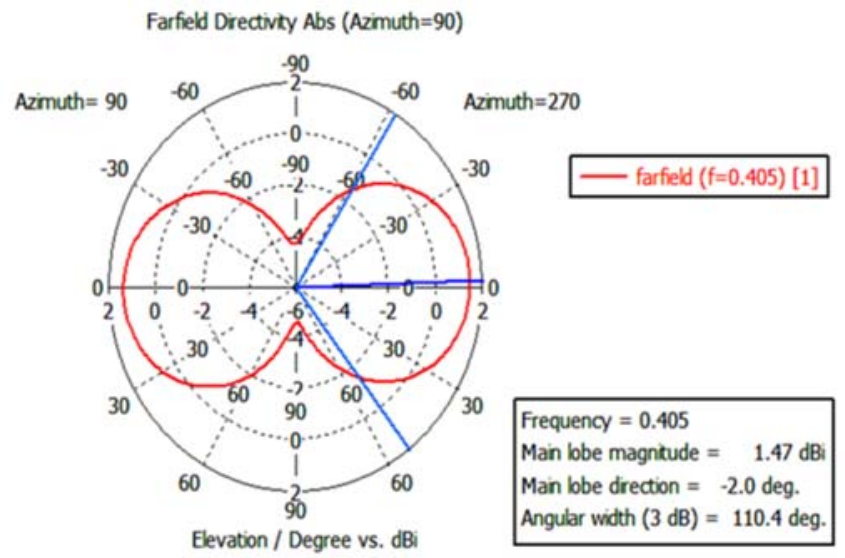

Figure 3. Polar view of E-shaped antenna (free space)

The radiation pattern is defined as a graphical representation of the radiation properties [12]. Far field region of antenna is dominated by radiated fields, with the E- and $\mathrm{H}$-fields orthogonal to each other [13]. Figures-3 and Figure-4 shows the radiation pattern of polar view and 3D view. The directivity and total radiation efficiency of this antenna is measured $1.688 \mathrm{dBi}$ and $-35.61 \mathrm{~dB}$ respectively.

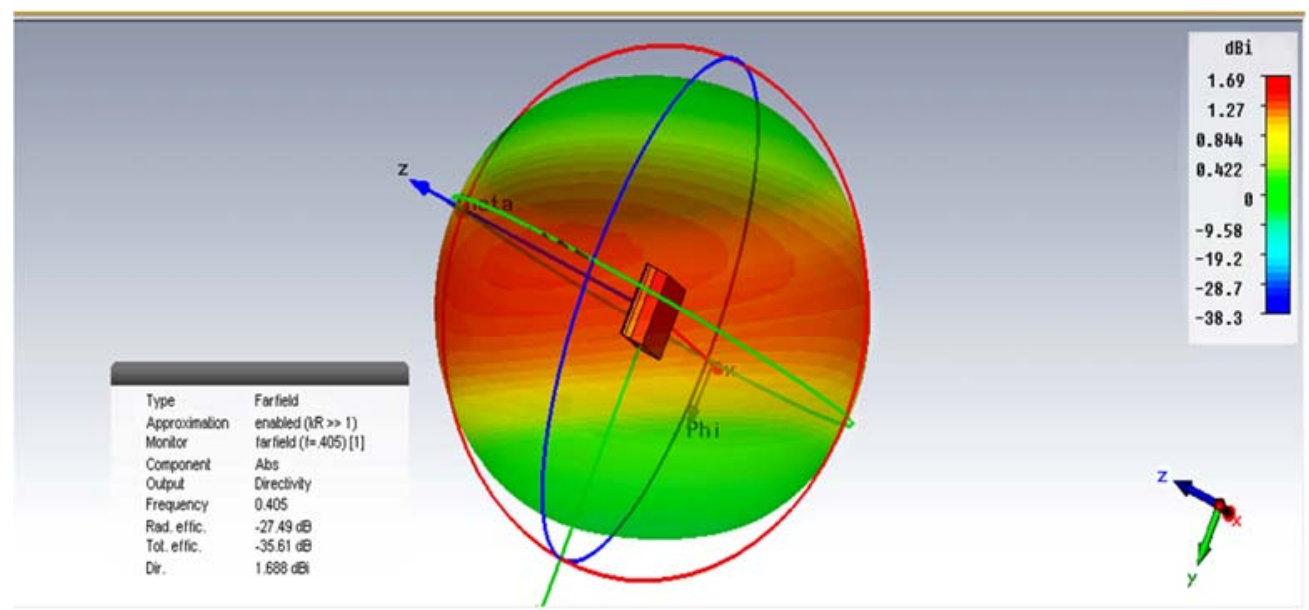

Figure 4. 3D view of Far-Field Region of the E-shaped antenna (free space)

In this design, Voltage Standing Wave Ratio (VSWR) is measured 1.350 at resonance frequency of $0.405 \mathrm{GHz}$ is shown in figure-5, which is satisfactory for batter antenna performance. By changing the conducting material, we found almost same results of VSWR It is measured by (1).

$$
V S W R=\frac{1+|\Gamma|}{1-|\Gamma|}
$$

VSWR is always a real and positive number for antennas [8]. 


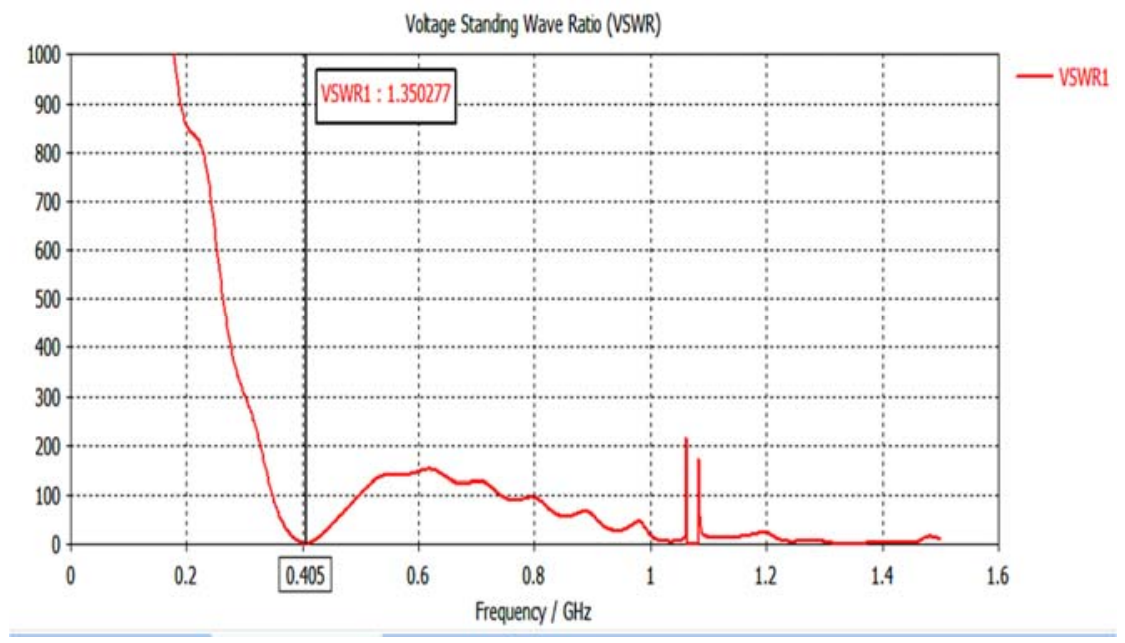

Figure 5. VSWR of E-shaped antenna (free space)

\subsection{Simulated E-shaped Antenna in Phantom Model}

A Human Phantom Mascel Model has been created with Skin $4 \mathrm{~mm}$, Fat $4 \mathrm{~mm}$ and the muscle $8 \mathrm{~mm}$. The antenna is implanted on that model for observing the performance at bio environment is shown in Figure 6. After implanting the antenna on phantom tissue, the $\mathrm{S} 11$ parameter is measured $-17.96 \mathrm{~dB}$ at resonance frequency, which ensure the biocompatibility of designed antenna is shown in Figure 7. In this analysis the resonance frequency is found $0.4046 \mathrm{GHz}$, which lies in MICS band.

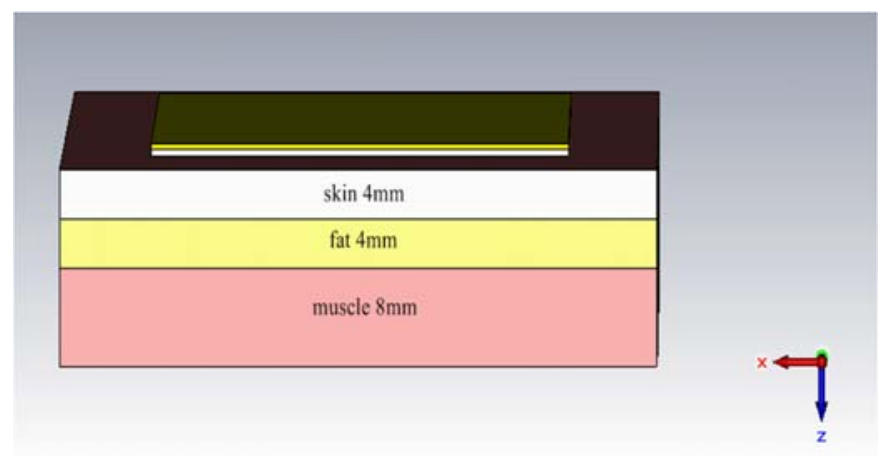

Figure 6. E-shaped Antenna placed on human phantom mascel model

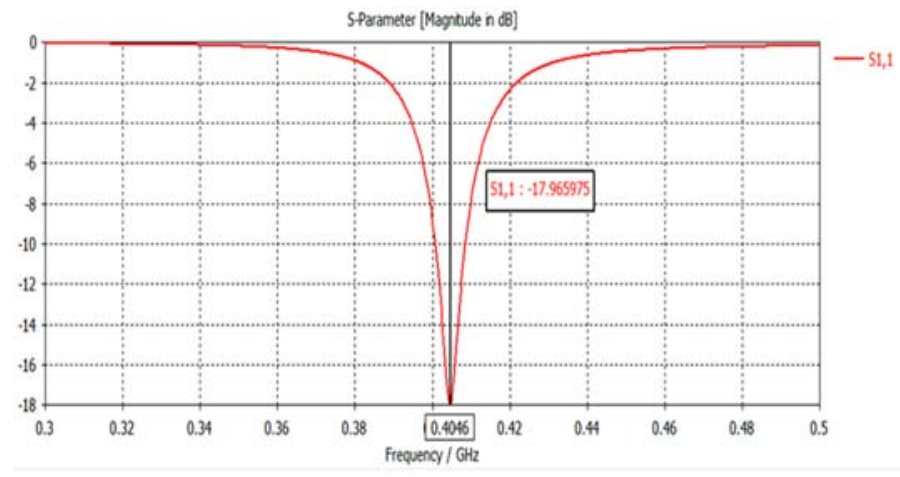

Figure 7. S11 parameter of E-shaped antenna into human phantom muscle model 
S11 parameter is also known as the reflection co-efficient [14]. Bandwidth of the antenna can be measured at $-10 \mathrm{~dB}$ by taking a line. From Figure 7 the bandwidth of this antenna is measured $8 \mathrm{MHz}(402 \mathrm{MHz}$ - 410MHz). Figure 8 shows the 3D view of far-field region of the E-shaped antenna after placing on human muscle model. Here the antenna directivity is observed $1.871 \mathrm{dBi}$. The total efficiency is found $-35.75 \mathrm{dBi}$. For all the conducting material, far-field region was observed. The directivity for other conducting materials is closed to this result.

In Figure 9 the VSWR is also observed on human tissue and found to be 1.3591 at resonant frequency of $405 \mathrm{MHz}$, which is good for impedance matching. Specific Absorption Rate (SAR) is determine the rate of energy absorption by human body, when RF energy is exposed.

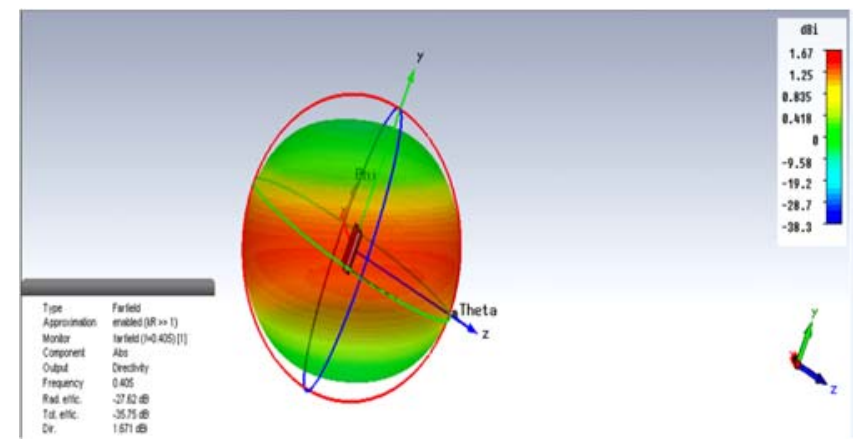

Figure 8. Far-field Radiation Pattern (3D view) on phantom muscle model

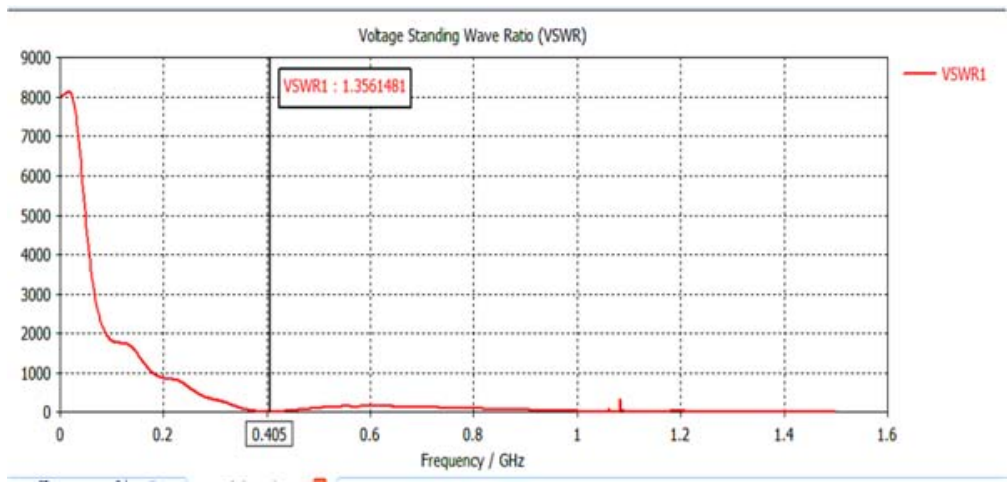

Figure 9. VSWR of the antenna on phantom muscle model

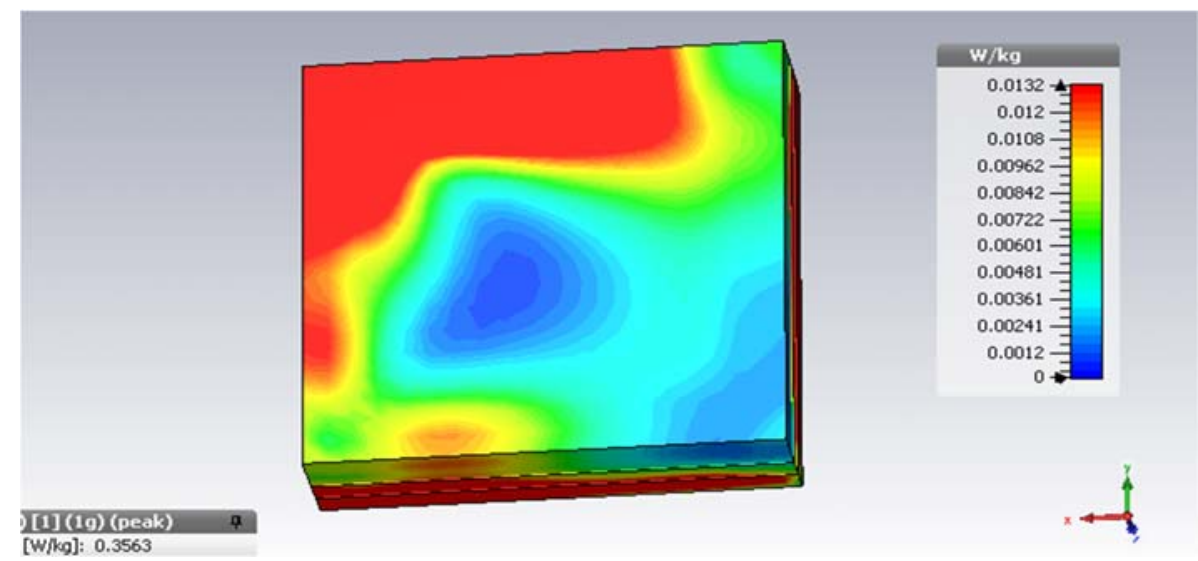

Figure 10. SAR distributions for an input of $1 \mathrm{~mW}$ on human phantom muscle model 
According to IEEE C95.3-2002 standard and also FCC and ICNIRP guidelines, SAR should not be exceeding $1.6 \mathrm{~W} / \mathrm{kg}$ for average 1 -g of tissue [15]. In Figure 10, the SAR is measured $0.3563 \mathrm{~W} / \mathrm{kg}$ for 1 gram of tissue, when the antenna is placed on human muscel model. From this observation we can say that, the radiation of antenna wil not be harmful for on body applications.

\section{CONCLUSION}

E-shaped patch antenna is designed in this research for biomedical application. This antenna is implanted on human phantom muscle model to test the workability in bio environment. The return loss is measured $-17.96 \mathrm{~dB}$ on human tissue at $405 \mathrm{MHz}$ frequency. VSWR is obtained 1.3591 of this designed antenna which indicates good impedence matching. SAR of $0.3563 \mathrm{~W} / \mathrm{kg}$ ensure the safety for on body application and make this antenna biocompatible.

\section{REFERENCES}

[1] Asimina Kiourti, Konstantina S. Nikita. A Review of Implantable Patch Antennas for Biomedical Telemetry: Challenges and Solutions. IEEE Antennas and Propagation Magazine. 2012: 54.

[2] Asimina Kiourti, Konstantina S. Nikita. Implantable Antennna. IEEE Microwave magazine. 2014.

[3] Zhuoqing Yang, Yi Zhang, Itoh, T. A flexible implantable micro temperature sensor on polymer capillary forbiomedical applications. 2013 IEEE 26th International Conference on Micro Electro Mechanical Systems(MEMS). 2013: 889-892.

[4] M. N. Islam and M. R. Yuce. Review of Medical Implant Communication System (MICS) band and network. ICT Express.2016; 2(4):188-194.

[5] R. F. Weir, P. R. Troyk, G. DeMichele, and T. Kuiken. Implantable myoelectric sensors (IMES) for upper-extremity prosthesis control. IEEE Eng. Med. Biol. Soc 25th Annu. Int. Conf. 2003: 1562-1565.

[6] R. Waterhouse. Small microstrip patch antenna. Electron. Letter. 1995; 31(8): 604.

[7] L. J. Chu. Physical limitations of omni-directional antenna. J. Appl. Phys., vol. 19, pp. 1163-1175, Dec. 1948.

[8] G. Sharma, D. Sharma and A. Katariya. An Approach to Design and Optimization of WLAN Patch Antennas for WiFi Applications. IJECCT 2(2),18-23

[9] M. Islam, R. Hasan, M. Haque, S. Ahmad, K. Mazed and M. Islam. In-body Antenna for Wireless Capsule Endoscopy at MICS Band. Computing Conference. London. 2018 (On proceeding).

[10] S. Wasiq, S. Gupta, V. K. Chandra and V. Varshney. Design and simulation of rhombus shaped microstrip patch antenna using HFSS. International Journal of Scientific Research and Management Studies (IJSRMS), vol.2, issue 2, pp. 97-104.

[11] K. Kim, S. Lee, E. Cho, J. Choi and S. Nam. Design of OOK system for wireless capsule endoscopy. Circuits and Systems (ISCAS), Proceedings of 2010 IEEE International Symposium on, pp. 1205-120, May 30 2010-June 22010.

[12] Constantine A. Balanis. ANTENNA THEORY ANALYSIS AND DESIGNING. Third Edition.

[13] A. C. Design, E. P. Systems, and T. Systems, Handbook of Antenna Technologies. Singapore: Springer Singapore, 2016.

[14] Raja Rashidul Hasan, Md. Azad Hossen Shanto, Sujan Howlader, Sharmin Jahan. A Novel Design and Miniaturization of a Scalp Implantable Circular Patch Antenna at ISM Band for Biomedical Application. Intelligent Systems Conference. London. 2017: 166-169.

[15] Nayak and B. R. Vengurlekar. Specific Absorption Rate (SAR) Effects on Human Beings Review. International Journal of Current Trends in Engineering \& Research (IJCTER).2016; 2(6): 518-522

Indo. J. Elec. Eng. \& Inf, Vol. 7, No. 1, March 2019: 151 - 156 